\title{
РОССИЙСКИЕ РЕГИОНЫ ЦВЕТНОЙ МЕТАЛЛУРГИИ: ВОЗМОЖНОСТИ ПЕРЕВООРУЖЕНИЯ ${ }^{1}$
}

Аннотация. В статье рассматривается импорт оборудования в российской изветной металлургии после 2014 г. на примере трёх компаний - «Норильского никеля», «Русала» и «Русской медной компании». Отдельное внимание уделено тем субъектам РФ, куда направляется значительная часть импортного оборудования, выявляются основнье компании и страньл-поставщики. Автор устанавливает различия в стратегии компаний иветной металлургии по закупкам необходимого оборудования в современных условиях.

Ключевые слова: ияетная металлургия, импорт оборудования, российские ТНК, субъекmbl $P \Phi$.

Введённые санкции в отношении России и проблемы в само́й российской экономике привели к резкому сокращению торговых отношений РФ по многим статьям, включая импорт одной из ключевых товарных позиций - машин и оборудования. Вопрос импортозамещения и замены стран-поставщиков на «восточных» партнёров стал одним из самых обсуждаемых в последнее время. К тому же почти пятилетний период, прошедший с момента введения санкций, даёт возможность оценить реально произошедшие изменения. В этом аспекте определённый интерес представляет процесс изменения в поставках оборудования в отраслях, не попавших под прямой запрет. К последним относится и цветная металлургия, чей технологический уровень на период до введения санкций оценивался приблизительно на среднемировом уровне при значительном отставании от стран, являющихся технологическими лидерами отрасли. При этом основное отставание отмечалось в производствах, непосредственно связанных с конечным потреблением².

В целом, согласно официальной статистике, средний возраст имеющихся машин и оборудования в России в секторе добычи полезных ископаемых в некоммерческих организациях составляет 10,2 года, в коммерческих - 7,9 лет, а степень износа основных фондов - 57,7\%. При этом изношенность и недостаток оборудования в секторе добычи полезных ископаемых не рассматривались руководителями предприятий в 2014-2015 гг. как основной фактор, ограничивающий рост производства. Более значимыми были высокий уровень налогообложения, недостаточный спрос на продукцию на внутреннем рынке и неопределённость экономической ситуации. В то же время в рамках цветной металлургии продолжался процесс ввода в

(C) Четверикова Анна Сергеевна - кандидат экономических наук, старший научный сотрудник Центра европейских исследований НИ ИМЭМО им. Е.М. Примакова РАН. Адрес: 117997, Россия, Москва, ул. Профсоюзная, д. 23. E-mail: chetverikova@imemo.ru.

DOI: http://dx.doi.org/10.15211/vestnikieran22019113118

${ }^{1}$ Статья подготовлена в рамках проекта «Регионы России в меняющемся мировом пространстве: анализ системных рисков развития, географии производства и импорта оборудования для ведущих отраслей, новых векторов экономического роста» программы Президиума РАН «Пространственная реструктуризация России с учётом геополитических, социально-экономических и геоэкологических вызовов».

${ }^{2}$ Сиваков Д.В., Буданов И.А. Аналитический доклад «Проблемы и перспективы развития отечественной цветной металлургии», 2010 г. С. 10, 12. URL: http://www.iacenter.ru/publication-files/122/102.pdf (дата обращения: 25.03.2019). 
действие производственных мощностей, хотя его объёмы и сократились после 2014 г. Например, было введено мощностей только на 200 тыс. т по переработке медной руды по сравнению с 1600 тыс. т в 2013 г. Резкие сокращения были отмечены и в отношении производственных мощностей золотосодержащей руды, а в производстве проката цветных металлов и первичного алюминия мощности и вовсе не вводились ${ }^{1}$. В целом показатель износа основных фондов в металлургии является одним из самых низких в промышленности - около 40\%, благодаря инвестициям за последние почти два десятилетия ${ }^{2}$.

С точки зрения финансовой устойчивости и, соответственно, способности к обновлению мощностей наилучшие позиции в цветной металлургии занимают крупнейшие компании, обладающие определённым запасом финансовой прочности. Но даже крупнейшие компании, такие как Уральская горно-металлургическая компания, относили проблемы с поставками передовых технологий, импортного оборудования и запасных частей для уже действующего оборудования к одному из главных влияний кризисных процессов на компанию. Так, в 2014 г. импорт технологического оборудования компании сократился на $20 \%$ по сравнению с 2013 г. ${ }^{3}$ Зависимость отдельных компаний отражает общую ситуацию в отрасли, характеризующуюся сильной зависимостью от зарубежных поставок машиностроительной продукции. В 2000-е гг. зависимость от импорта в тяжёлом машиностроении только увеличивалась и составила более $58 \%$ в 2011 г. В секторе горнодобывающей и строительной техники и металлургического машиностроения в 2012 г. коэффициент покрытия импорта экспортом составлял только $5 \%$ и $11 \%$ соответственно ${ }^{4}$.

Несмотря на текущие условия, крупнейшие металлургические компании продолжали процесс модернизации собственных мощностей, к которым относились и лидеры российской цветной металлургии ГМК «Норильский никель» и «Русал» (табл. 1), отличающиеся между собой как специализацией, так и географией деятельности внутри РФ и за её пределами. Уступая им в разы по финансовым показателям и численности занятых, «Русская медная компания», однако, сравнима с лидерами по географии присутствия в России. В то же время все три компании представляют собой примеры различных стратегий поведения в ухудшившихся политико-экономических условиях, при действии санкций и активизации политики импортозамещения в России в целом.

Таблица 1

Российские компании цветной металлургии, 2018 г.

\begin{tabular}{|l|l|c|c|c|c|}
\hline \multicolumn{1}{|c|}{ Компания } & \multicolumn{1}{|c|}{ Специализация } & $\begin{array}{c}\text { Выручка, } \\
\text { млрд долл. }\end{array}$ & $\begin{array}{c}\text { Чистая прибыль, } \\
\text { млрд долл. }\end{array}$ & $\begin{array}{c}\text { Занятость, } \\
\text { тыс. человек }\end{array}$ & $\begin{array}{c}\text { Число основных } \\
\text { субъектов РФ }\end{array}$ \\
\hline $\begin{array}{l}\text { ГМК «Норильский } \\
\text { никель» }\end{array}$ & $\begin{array}{l}\text { никель, медь, плати- } \\
\text { на, палладий и др. }\end{array}$ & 11,7 & 3,1 & 79 & 3 \\
\hline ОК «Русал» & алюминий, глинозем & 10,3 & 1,7 & 62 & 11 \\
\hline $\begin{array}{l}\text { «усская медная } \\
\text { компания»* }\end{array}$ & $\begin{array}{l}\text { медь, цинк, золото, } \\
\text { серебро }\end{array}$ & 2,3 & 0,3 & 10 & 5 \\
\hline
\end{tabular}

Составлено по: информации официальных сайтов компаний.

* - данные за 2017 г.

За прошедшие годы сложившиеся условия не вынудили «Норильский никель», «Русал» и «Русскую медную компанию» отказаться полностью от импортного оборудования и перей-

\footnotetext{
${ }_{1}^{1}$ Промышленное производство в России. 2016: стат. сб. Росстат. М., 2016. С. 63, 124.

${ }_{2}^{2}$ Адно Ю.Л. «Макроэкономические аспекты развития металлургии». Сталь, №5, 2018 г. С. 67.

${ }^{3}$ Козицын А.А., Дудинская М.В. «Конкурентоспособность и экономическая безопасность - приоритетные задачи металлургического комплекса региона и его лидеров в условиях нестабильности». Экономика региона, №3, 2015 г. С. 207-208.

${ }^{4}$ Борисов В.Н., Почукаева О.В. «Инновационное машиностроение как фактор развивающего импортозамещения». Проблемы прогнозирования, №3(150), 2015 г. С. 34-35.
} 
ти на продукцию отечественных производителей, хотя масштабы закупок и снизились. Среди анализируемых компаний наиболее активно обновлял оборудование за счёт импорта «Норильский никель», который заменял или ставил дополнительное новое оборудование во всех трёх субъектах РФ своего присутствия (табл. 2). При этом компания использовала иностранную технику преимущественно в случаях отсутствия отечественных аналогов. А по итогам 2017 г. иностранные поставщики составляли только около 7\% всех поставщиков «Норильского никеля», что соответствовало средним значениям последних лет ${ }^{1}$ (в 2014 г. доля зарубежных поставщиков составляла около 8\%). Хотя ранее, в 2013 г., компания открыто заявляла о замене российского оборудования на иностранное. Невозможность полного отказа компании от импорта обусловлена несколькими объективными факторами, включая изначальное строительство мощностей ещё в советский период с участием иностранных специалистов и техники, например, финских. История создания вынуждает «Норильский никель» и сейчас закупать различное финское оборудование, при этом традиционными поставщиками являются и немецкие компании, и шведские, и другие европейские. Кроме того, компания приобретала в последние годы технику из США и Японии. Тем самым, с 2013 г. география закупок оборудо-вания «Норильского никеля» не претерпела кардинальных изменений, не произошло полного импортозамещения или поворота в «восточном направлении».

Таблица 2

Закупка импортного оборудования российскими компаниями цветной металлургии,

\begin{tabular}{|c|c|c|}
\hline Компания & Субъект РФ & Страна-поставщик/ компания-поставщик \\
\hline \multirow{3}{*}{$\begin{array}{l}\text { ГМК } \\
\text { «Норильский } \\
\text { никель» }\end{array}$} & Забайкальский край & $\begin{array}{l}\text { Германия (Liebherr); Дания (FL Smidth); США (Caterpillar); Финляндия } \\
\text { (Outotec); Швеция (Sandvik) Япония (Komatsu) }\end{array}$ \\
\hline & Красноярский край & $\begin{array}{l}\text { Великобритания (Weir Group); Германия (Engineering Dobersek, Funke- } \\
\text { Huster, Liebherr, Paus, Siemag Tecberg, Siemens); США (Caterpillar, General } \\
\text { Electric, Howden, Hyster); Финляндия (Metso, Normet Group, Outotec); } \\
\text { Чехия (Ferrit); Швеция (Atlas Сорсо, Sandvik) }\end{array}$ \\
\hline & Мурманская область & $\begin{array}{l}\text { Великобритания (Malcolm Barnett\&Associates, Weir Group); Германия } \\
\text { (Ebner, Flottweg, Liebherr, Linde, Siemens); Дания (FL Smidth); Нидерлан- } \\
\text { ды (Darley); США (Caterpillar); Финляндия (Metso, Normet Group, } \\
\text { Outotec); Швейцария (Evatherm); Швеция (Atlas Copco) }\end{array}$ \\
\hline \multirow{5}{*}{ ОК «Русал» } & Иркутская область & Италия (Befesa Aluminio); Франция (Alstom) \\
\hline & Республика Коми & Германия (Liebherr); Финляндия (Sleipner); Япония (Komatsu) \\
\hline & Красноярский край & $\begin{array}{l}\text { Австралия (O.D.T. Engineering Pty.), Германия (Liebherr, NKM Noell); } \\
\text { Италия (н.д.), Канада (н.д.), Нидерланды (Hencon), Польша (н.д.), США } \\
\text { (Caterpillar); Франция (н.д.), Швеция (Atlas Copco); Япония (Komatsu) }\end{array}$ \\
\hline & Свердловская область & Германия (Fahrzeuge); Швеция (Boomer, Sandvik) \\
\hline & Республика Хакасия & Италия (Contibuus-Properzi), Норвегия (н.д.) \\
\hline \multirow[b]{2}{*}{$\begin{array}{l}\text { «Русская } \\
\text { медная } \\
\text { компания» }\end{array}$} & Новгородская область & Германия (Aqseptence Group) \\
\hline & Челябинская область & $\begin{array}{l}\text { Германия (Linde, LUHR), Испания (TN Minerals), Канада (Advanced } \\
\text { Dynamic), США (Leco, Pettibone, Southwire), Финляндия (Kumera, Metso, } \\
\text { Outotec); Швеция (Atlas Copco); Япония (Komatsu) }\end{array}$ \\
\hline
\end{tabular}

Составлено по: официальным годовым отчётам и отчётам об устойчивом развитии компаний за 2013-2017 гг., информации официальных сайтов компаний, данным СМИ.

«Русал», в отношении которого применяются санкционные условия, ещё в 2014 г. объявил программу импортозамещения спецтехники для своих алюминиевых заводов на базе отдельного подразделения в г. Красноярске. За шесть лет компания поставила почти 170 единиц техники собственного производства ${ }^{3}$, однако это не исключило закупку иностранного обору-

\footnotetext{
${ }^{1}$ Норникель. Годовой отчёт 2017. Инвестируя в устойчивое развитие. C. 106. URL: https://www.nornickel.ru/in vestors/disclosure/annual-reports/ (дата обращения: 25.03.2019).

2 В таблицу вошли субъекты РФ, упоминавшиеся в официальных новостях компаний и отчётах за рассматриваемый период.

3 Русал. Пресс-релиз 28.11.2018. URL: https://rusal.ru/press-center/press-releases/23538/?sphrase_id=93528 (дата Научно-аналитический вестник ИЕ РАН, 2019, №2
} 
дования. Стоит отметить, что «Русал» менее склонен, по сравнению с «Норильским никелем», к импорту иностранного оборудования и в последние годы нечасто публикует подобную информацию. Однако в ключевые регионы деятельности компании поступает оборудование преимущественно из Европы, а также из Австралии, Канады, США и Японии, которое устанавливается как в процессе модернизации, так и при строительстве новых мощностей.

«Русская медная компания» в некоторой степени повторяет стратегию «Норильского никеля» в закупке оборудования, но в значительно меньших масштабах: компания приобретала как российскую, так и иностранную технику в случае перевооружения или расширения мощностей. В силу финансовых возможностей география импорта не так широка: традиционными поставщиками РМК являются немецкие и финские компании, однако в последние годы оборудование закупалось и в других европейских странах, а также в Канаде, США и Японии.

Отдельно стоит упомянуть тот факт, что российские компании закупают за рубежом не только специфическое горнодобывающее или индустриальное оборудование, но и вспомогательную технику, включая экскаваторы, автопогрузчики и пр. Кроме того, компании приобретают и «условно российское» оборудование - продукцию российских дочерних структур основных мировых производителей.

Деятельность трёх металлургических компаний в последние годы позволяет говорить о том, что вне зависимости от размера компании, её географии деятельности в России, наличия цели импортозамещения полностью отказаться от импорта оборудования остаётся невозможным: российское машиностроение не в состоянии полностью обеспечить цветную металлургию необходимыми аналогами. При этом импорт оборудования снижается, что подтверждается на уровне региональной статистики (табл. 3). Среди 9 субъектов РФ, в которые «Норильский никель», «Русал» и «Русская медная компания» импортировали оборудование, только в двух регионах объёмы импорта машин и оборудования превысили уровень 2013 г. в 2017 г., когда начало наблюдаться восстановление внешней торговли, - это Мурманская область и Забайкальский край, где велись крупные инвестиционные проекты. При этом более быстрые темпы восстановления импорта машин и оборудования по сравнению с общим импортом увеличили доли этой статьи в четырёх регионах: Забайкальском крае, Мурманской и Свердловской областях, Республике Хакассия, что лишний раз подтвердило важность импортного оборудования в целом, а не только металлургического для экономик отдельных субъектов РФ.

Таблица 3

Динамика импорта субъектов РФ

\begin{tabular}{|l|c|c|c|c|c|}
\hline \multicolumn{1}{|c|}{ Показатель, И* ( М**) } & $\mathbf{2 0 1 3}$ г. & $\mathbf{2 0 1 4}$ г. & $\mathbf{2 0 1 5}$ г. & $\mathbf{2 0 1 6}$ г. & $\mathbf{2 0 1 7}$ г. \\
\hline Забайкальский край & $537(21,8 \%)$ & $555(18,2 \%)$ & $462(19,0 \%)$ & $411(16,8 \%)$ & $590(23,6 \%)$ \\
\hline Иркутская область & $1174(35,6 \%)$ & $1553(30,3 \%)$ & $1388(27,4 \%)$ & $1016(21,9 \%)$ & $1257(26,5 \%)$ \\
\hline Красноярский край & $2099(50,6 \%)$ & $1479(40,7 \%)$ & $1487(39,9 \%)$ & $1237(51,9 \%)$ & $1301(45,7 \%)$ \\
\hline Республика Коми & $298(55,0 \%)$ & $251(43,8 \%)$ & $174(44,3 \%)$ & $126(27,0 \%)$ & $134(21,6 \%)$ \\
\hline Мурманская область & $778(25,2 \%)$ & $449(29,0 \%)$ & $366(46,7 \%)$ & $395(46,7 \%)$ & $358(59,2 \%)$ \\
\hline Новгородская область & $710(24,6 \%)$ & $769(29,1 \%)$ & $623(34,3 \%)$ & $437(20,6 \%)$ & $389(22,4 \%)$ \\
\hline Свердловская область & $4177(26,5 \%)$ & $3706(46,5 \%)$ & $3058(44,2 \%)$ & $2551(36,1 \%)$ & $3710(36,3 \%)$ \\
\hline Республика Хакасия & $573(7,5 \%)$ & $329(12,2 \%)$ & $296(11,5 \%)$ & $250(18,0 \%)$ & $299(14,0 \%)$ \\
\hline Челябинская область & $4022(39,5 \%)$ & $2761(36,0 \%)$ & $1969(25,1 \%)$ & $1836(29,7 \%)$ & $2697(35,1 \%)$ \\
\hline
\end{tabular}

Составлено по: официальная статистика субъектов РФ, Регионы России. Социально-экономические показатели 2013-2018.

* - импорт всего, млн долл.

** - доля машин, оборудования, транспортных средств в общем импорте.

Практика крупнейших российских компаний цветной металлургии свидетельствует о том, что даже при стремлении компаний к импортозамещению в секторе машин и оборудова-

обращения: 25.03.2019).

Научно-аналитический вестник ИЕ РАН, 2019, №2 
ния и при наличии стимулирующих факторов в виде экономической ситуации, включая курс рубля, полностью отказа от импортных поставок не происходит. Причиной складывающейся ситуации является неспособность России поднять машиностроительную отрасль и перевести её на новый технологический уровень только за счёт собственных ресурсов, что обуславливается в свою очередь необходимостью обновления оборудования на $60 \%$ за счёт импорта ${ }^{1}$. По оценкам специалистов, наиболее быстрыми темпами должен расти импорт металлообрабатывающего оборудования, а также продукции приборостроения и электроники ${ }^{2}$. Кроме того, деятельность российских ТНК за прошедшие годы показала, что основные поставщики остаются прежними - это европейские производители, а также американские, канадские и японские компании. Улучшения во внешнеторговой сфере РФ в последние два года и экономической ситуации позволяют говорить о том, что текущие тенденции в импорте оборудования и техники в цветной металлургии сохранятся.

\section{Список литературы}

Адно Ю.Л. «Макроэкономические аспекты развития металлургии». Сталь, №5, 2018 г. C. $62-69$.

Борисов В.Н., Почукаева О.В. «Инновационное машиностроение как фактор развивающего импортозамещения». Проблемы прогнозирования, №3(150), 2015 г. С. 31-42.

Козицын А.А., Дудинская М.В. «Конкурентоспособность и экономическая безопасность приоритетные задачи металлургического комплекса региона и его лидеров в условиях нестабильности». Экономика региона, №3, 2015 г. С. 204-215.

Норникель. Годовой отчёт 2017. Инвестируя в устойчивое развитие. 312 с. URL: https://www.nornickel.ru/investors/disclosure/annual-reports/ (дата обращения: 25.03.2019).

Оболенский В.П., Квашнина И.А., Шуйский В.П. «Использование внешних источников для перевооружения российской экономики». Российский внешнеэкономический вестник, №11, 2016 г. С. 3-17.

Промышленное производство в России. 2016: стат. сб. / Росстат. М., 2016. 347 с.

Русал. Пресс-релиз 28.11.2018. URL: https://rusal.ru/press-center/press-releases/23538/ ?sphrase_id=93528 (дата обращения: 25.03.2019).

Сиваков Д.В., Буданов И.А. Аналитический доклад «Проблемы и перспективы развития отечественной цветной металлургии». 2010 г. 40 c. URL: http://www.iacenter.ru/publicationfiles/122/102.pdf (дата обращения: 25.03.2019).

Шуйский В.П. «Реиндустриализация России: возможности импорта технологий». Российский внешнеэкономический вестник, №3, 2014 г. С. 28-37.

\section{References}

Adno Y.L. «Macroeconomic aspects of development of metallurgy». Stal’, №5, 2018. P. 62-69.

Borisov V.N., Pochukaeva O.V. «Innovating machine engineering as a factor of developing import substitution». Problemy prognozirovanija, №3(150), 2015. P. 31-42.

Kozitsyn A.A., Dudinskaya M.V. «Competitiveness and economic security - the priority problems of region's metallurgical complex and its leaders in the conditions of instability». Economy of

\footnotetext{
${ }^{1}$ Оболенский В.П., Квашнина И.А., Шуйский В.П. «Использование внешних источников для перевооружения российской экономики». Российский внешнеэкономический вестник, №11, 2016 г. С. 4-5.

${ }^{2}$ Шуйский В.П. «Реиндустриализация России: возможности импорта технологий». Российский внешнеэкономический вестник, №3, 2014 г. С. 31.
}

Научно-аналитический вестник ИЕ РАН, 2019, №2 
region, №3, 2015. P. 204-215.

Nornikel. Annual report 2017. Investing in sustainable development. 312 p. URL: https://www.nornickel.ru/investors/disclosure/annual-reports/ (accessed: 25.03.2019).

Obolenskiy V.P., Kvashnina I.A., Shuiyskiy V.P. «Using foreign sources for tech re-equipment of Russia’s economy», Russian foreign economic journal, №11, 2016. P. 3-17.

Industrial production in Russia. 2016: stat. coll. / Rosstat. M., 2016. 347 p.

Rusal. Press release 28.11.2018. URL: https://rusal.ru/press-center/press-releases/23538/ ?sphrase_id=93528 (accessed: 25.03.2019).

Sivakov D.V., Budanov I.A. Analytical report «Problems and prospects of development of domestic non-ferrous metallurgy», 2010. 40 p. URL: http://www.iacenter.ru/publicationfiles/122/102.pdf (accessed: 25.03.2019).

Shuyskiy V.P. «Reindustrialization of Russia: possibilities of technology imports». Russian foreign economic journal, №3, 2014. P. 28-37.

\section{The Russian Regions of the Non-ferrous Metallurgy: The Possibilities of the Rearmament}

Author. Anna Chetverikova, Candidate of Sciences (Economics), Senior Research Associate, Centre for European Studies, Primakov Institute of World Economy and International Relations, Russian Academy of Sciences (IMEMO RAS). Address: 23, Profsoyuznaya str., Moscow, Russia, 117997. E-mail: chetverikova@imemo.ru.

Abstract. The paper analyses the import of the equipment in the Russian non-ferrous metallurgy after 2014 addressing three companies - MMC Norilsk Nickel, RUSAL and Russian Copper Company. Special attention is paid to the regions of the Russian Federation where a significant part of imported equipment is sent; the main companies and supplier countries are identified. The author points out the differences in the strategies of non-ferrous metallurgy companies in the procurement of necessary equipment in the current political and economic conditions.

Key words: non-ferrous metallurgy, equipment import, Russian TNCs, regions of the RF

DOI: http://dx.doi.org/10.15211/vestnikieran22019113118 